\title{
Gender Differences in the Use of Lexical Hedges in Academic Spoken Language among Iranian EFL Learners: A Comparative Study
}

\section{Ehsan Namaziandost ${ }^{1 *}$, Sajad Shafiee ${ }^{1}$}

\footnotetext{
*Correspondence:

e.namaziandost@std.iaushk.ac.ir

${ }^{1}$ Department of English, Faculty of

Humanities, Shahrekord Branch,

Islamic Azad University, Shahrekord,

Iran
}

Received: 1 September 2018

Revision: 2 October, 2018

Accepted: 19 October 2018

Published online: 20 December 2018

\begin{abstract}
This study tried to compare the possible differences between female and male EFL students with respect to the use of lexical hedges in their academic spoken language. To fulfil this objective, 40 Iranian upper-intermediate EFL learners majoring in TEFL were chosen from Islamic Azad University of Abadan, Iran. The selected participants were assigned into two equal groups namely male group $(n=20)$ and female group $(n=20)$. Then, five discussion sessions in a single gendered context were separately recorded for male and female participants. Frequency counts and chi-square were used to analyze the obtained data. By utilizing the framework of hedges, it is deduced that that there are differences among female and male respondents' propensity in selecting word of lexical hedges. Female responders tend to utilize more lexical hedges than male responders. In such manner, most frequently lexical hedges of fillers such as; hmm, uhh, you know, yeah were used most frequently by female respondents in their utterances; while male respondents most repeatedly utilized lexical hedges of fillers like; I think, uhh, yeah in their utterances. Female respondents had broad range variegation in picking words of lexical hedges while male respondents were not sufficiently productive in selecting the words of lexical hedges. It was demonstrated by the number of lexical hedges applied in giving viewpoints in debate and discussion context.
\end{abstract}

Keywords: academic spoken language, discussion, gender differences, lexical hedges 


\section{Introduction}

In spoken language, a great part of the meaning is specified by the unique situation. This appears differently in relation to composed language, where more implications are given straightforwardly by the content. In spoken language, reality of a theorem is characterized by common-sense reference to understanding, though in composed language a more noteworthy accentuation is set on consistent and coherent contention; correspondingly, spoken language tends to shift intellectual data, containing the connection between the speaker and the grandstand, while composed language tends to convey objective data (Rosanti \& Jaelani, 2016).

Since language has diverse shape, it causes the distinctions in the utilization of language channel. The distinctions can be seen agreement with part of expressions, phonology, and morphology. The morphological distinction is identified with the sex of speakers. Lakoff (1972) states that, "the distinctions in utilizing language amongst males and females are diverse morphologically in light of the fact that females are described by semantic highlights or phonetic structures." Also, she embodies that the distinction of phonetic highlights by females is in utilizing lexical hedges, e.g. you know, sort of, well, you see. Most ladies repeatedly utilize linguistic highlights than men while communicating an idea. This announcement is bolstered by Lakoff (1972 as cited in Holmes, 2008, p.300), he clarifies that "ladies utilized more hedging and boosting gadgets than men." Hedging and boosting here are characterized by Lakoff (1972 as cited in Holmes, 2008, p.299) as "various linguistic highlights which were bound together by their capacity of communicating absence of certainty or demonstrating the declaration of vulnerability or uncertainty."

In this way, in utilizing the language as a marvel of linguistics, there are varieties with respect to human sexual orientation. That wonder can be watched effectively in spoken frame, for instance in debate and discussions. It can be viewed effectively in debate, since individuals give distinctive ideas about something. There will be some linguistic properties, here is the utilization of lexical hedges in spoken language. Subsequently, the contrasts amongst women and men in spoken language will show up in their linguistic characteristics. In discussing or giving ideas, women and men will fluctuate. It is conceivable that women will apply lexical hedges more than men. Holmes repeats Lakoff's hypothesis (2008, p.298): "ladies are described by linguistics highlights, for example, lexical hedges." The language utilized amongst female and male students is diverse in a few viewpoints. It can be seen from the properties of ladies' semantic highlights, for example, in utilizing lexical hedges.

\subsection{Research Questions}

RQ 1. What lexical hedges were frequently used by female and male students in academic spoken language?

RQ 2. Is there any significant difference between Iranian female and male students in terms of the employed lexical hedges in academic spoken language?

\section{Review of the Literature}

\subsection{Theoretical Background}

Language is a type of social connection of individuals, either women or men that happens in concrete circumstance. Moreover, language is not only as a social sign but also individual. Language as a social sign implies that it is not only chosen by etymological factor but also social and circumstance. The instances of social factor are foundations of instruction, economic wellbeing, age, sex, gender and etc. Also, Holmes (2008) epitomizes the situational factor, for example, the member (who is talking, who are they addressing), the setting or social setting (where are they talking), the theme (what is it about), and etc. Along these lines, language has fundamental part of society and it is impacted additionally by sexual orientation.

In the general public life, individuals are hovered by information of sexual orientation. As per Holmes (2008), the term gender is utilized to separate individuals as indicated by socio-cultural practices, for example, speech. Likewise, Tong (2009, p.51) epitomizes that "there is a reality utilized by society as the establishment of developing a masculine 
and feminine as sexual orientation personality." There are a few differences between men's speech and women's speech. When all is said in done, men's speech was viewed as intelligent, succinct, and managing essential points, while ladies' speech was appraised as enthusiastic, extravagant, befuddled, and longwinded. This statement is upheld by Lakoff's hypothesis in Holmes (2008, p.297). She asserts that "various linguistic properties were utilized more frequently by females than by males, since females regularly express vulnerability and absence of trust in speech."

\subsubsection{Spoken Language}

Spoken language is a language which is talked orally and it is in form of sounds. Spoken language sometimes is called oral language. This language is delivered in its unconstrained shape. This announcement is bolstered by Halliday (1985, p.46) "unconstrained discussion as the characteristic type of spoken language." In spoken language, most implications are dictated by the unique situation. As indicated by Tannen (1982, p.167), "spoken language demonstrates phenomena as procedures." Then again, spoken language tends to have a lower lexical density than composed language. Moreover, Tannen (1982, p.195), includes, "spoken language is a type of communication in which individuals utilize the mouth to make conspicuous sounds."

Leech, Deuchar, and Hoogenraad (1982, p.136) clarify that spoken language may stand to be less unequivocal as any correspondence in light of the fact that: firstly, it is joined by non-verbal communication. Secondly, "the prompt physical condition can be alluded to." Thirdly, members share normal information. At last, a prompt feedback is given. Subsequently if there is a token of misconception or incomprehension, the message might be illuminated or rehashed.

\subsubsection{Hedges}

Hedges are likewise called hedging. Hedging has gotten much consideration in connection to conversational guidelines as an intend to encourage turn-taking, respectfulness, moderate face-dangers, yet it is additionally viewed as a method for conveying ambiguity intentionally. Respectfulness and hedging have progressed toward becoming types of social interpretation of verbal and non-verbal behavior rotating around the idea of concealing any hint of failure confront. Accordingly, they assume a vital part in social communication techniques. In language researches, hedging has come to assign a sign of language by methods for which speakers take prudent steps to shield themselves from the negative impact of their idioms or to shield themselves or their conversationalists from any damage to the idea of face caused by their utterances.

Lakoff (1972, p.271) investigates hedges as, "words whose meaning verifiably includes fluffiness-words whose activity is to make things fuzzier or less fluffy." He expresses that words and expressions show hedging force (like rather, very, in a manner of speaking) which defines a few limits in how to interpret linguistic cases as hedges. Lakoff (1972, p.213) includes hedges, "cooperate with felicity conditions for articulations and with principles of discussion." Therefore, setting the directions for deciphering hedges is signs which are conditioned by realistic components.

Hedging indicates an urgent part of language as the proper utilization of hedges mirrors a high level of proficiency in social association by exhibiting the capacity to express degrees of sureness and acing expository methodologies required under conversational conditions: "Hedging alludes to any linguistic means used to show either (a) an absence of complete commitment to reality estimation of an accompanying recommendation, or (b) a will not to express that responsibility completely" (Hyland, 1998, p.1). The investigation of hedging has been extended over the past twenty years. Literature incorporates different tasks on the topic and various names are utilized to mean this classification, for example, conditioners (Crystal \& Davy, 1975), weakeners (Brown \& Levinson, 1978, 1987), downgraders (House \& Kasper, 1981), compromisers (James, 1983), uncertainty (Holmes, 1983), modest representation of the truth (Hübler, 1983), evidentiality (Chafe, 1986), downtoners (Greenbaum \& Quirk, 1990), diminishers/downtoners (Biber $\&$ Leech,1999), and stance markers (Atkinson, 1999). 
Namasaraev (1997, p.67) recognizes 4 parameters that portray hedging systems: (1) Indetermination - including a level of fluffiness or vulnerability to a solitary word or lump of language; (2) Depersonalization - maintaining a strategic distance from coordinate reference by utilizing "we" or "the creators" or some other indifferent subjects; (3) Subjectivisation - utilizing I + think/assume, expect and different verbs of reasoning with the motivation behind flagging the subjectivity of what is stated, as an individual view rather than the complete truth; (5) Limitation expelling fluffiness or dubiousness from a piece of a content by constraining classification membership.

A hedge is a relieving word or sound used to diminish the effect of an expression. Regularly, hedges can be adjectives or adverbs, yet can likewise comprise clauses (Rosanti \& Jaelani, 2016). It could be viewed as a type of euphemism.

Examples:

1. There might just be a few insignificant problems we need to address (adjective).

2. The party was somewhat spoiled by the return of the parents (adverb).

3. I'm not an expert but you might want to try restarting your computer (clause) (Rosanti \& Jaelani, 2016).

Hedges may deliberately or unexpectedly be utilized in both spoken and composed language since they are essentially imperative in correspondence. Hedges encourage speakers and scholars demonstrate more decisively how Gricean maxims (expectations of quantity, quality, manner, and relevance) are seen in evaluations. For example,

1. All I know is smoking is harmful to your health.

In (1), it can be viewed that information transmitted by the speaker is restricted by adding all I know and as you maybe know. In this manner, the speaker needs to advise that she is not just making a statement however the maxim of quantity also.

2. They told me that they are married.

In the event that the speaker just says that "they are married" and they do not know without a doubt if chance that they are married, they may disregard the maxim of quality since they say something that they do not know to be valid or false. In any case, by adding they revealed to me that, the speaker needs to affirm that they are watching the conversational maxim of quality.

3. I am not sure if all of these are clear to you, but this is what I know.

The above case (3) demonstrates that hedges are great signs the speakers are aware of the maxim of manner, as well as endeavoring to watch them.

4. By the way, you like this car?

By utilizing incidentally, what has been said by the speakers is not applicable to the minute in which the discussion happens. Such a hedge can be found amidst speakers' discussion as the speaker needs to change to another topic that is not quite the same as the past one. Consequently, by the way functions as a hedge demonstrating that the speaker needs to float into another point or to stop the past theme (Rosanti \& Jaelani, 2016).

Lakoff, in a large portion of her work on females and language, asserts that females utilize hedges more as often as possible than males do. She even places hedge as one of the highlights in women's discussion. Holmes (2008) notices that Lakoff's investigation on the hedges indicates women do not have enough certainty when engaged with a discussion. Skarda (as cited in Eckert, 2003, p.394), however, exhibited cases of hedge such as, like, you know, I mean, contending that they do not particularly have a place with female element of talk.

Zimmerman and West (1975) propose the possibility that hedges like um, hmm, uh huh, yeah are frequently utilized to demonstrate a functioning hearership, in that listeners persistently indicate enthusiasm for the speaker's expressions. 
These hedges consequently cover with the continuous talk or therefore happen after expressions created by the speaker. In communicate talk, the event of hedges among the interactants is clearly unavoidable. Adams and Hicks (2001) say that the fence uh huh is regularly vocalized and a gesture simultaneously happens, which is either unmistakably or somewhat appeared. They likewise assert that the hedge functions as a 'verbal encourager' which is considered as supportive.

Male and female has many differences, it could be indicated when they state something, for instance in expressing their idea about something (Rosanti \& Jaelani, 2016). Lakoff proposed that women's speech was determined by linguistic features such as the following:

a. Lexical hedge or fillers, e.g. you know, sort of, well, you see.

b. Tag question, e.g. she's very nice, isn't she?

c. Rising intonation or declarative, e.g. it's really good.

d. 'Empty' adjectives, e.g. divine, charming, cute.

e. Precise color terms, e.g. magenta, aquamarine.

f. Intensifier such as just and so, e.g. I like him so much.

g. 'Hypercorrection' grammar, e.g. consistent use of standard verb forms.

h. 'Super polite' forms, e.g. indirect request, euphemism.

i. Avoidance of strong swears words, e.g. fudge, my goodness.

j. Emphatic stress, e.g. it was a BRILLIANT performance (Rosanti \& Jaelani, 2016).

Namasaraev (1997, p.153) believes that, "There are nine kinds of lexical hedges in terms of its classification." The following table illustrates language utilized in hedging based on its classification. 
Table 1. Classification of hedging

\begin{tabular}{|c|c|c|}
\hline Classification & Words & Sample Sentences \\
\hline $\begin{array}{l}\text { Modal auxiliary } \\
\text { verb }\end{array}$ & $\begin{array}{l}\text { will, must, might, can, should, could, } \\
\text { would, may }\end{array}$ & $\begin{array}{l}\text { 'Such a measure might be more sensitive to changes in } \\
\text { health after specialist treatment.' }\end{array}$ \\
\hline Lexical verb & $\begin{array}{l}\text { appear, believe, assume, tend, } \\
\text { suggest, estimate, think, argue, } \\
\text { speculate, indicate, seem, propose, } \\
\text { suppose }\end{array}$ & $\begin{array}{l}\text { 'In spite of its limitations, the study appears to have a } \\
\text { number of important strengths.' }\end{array}$ \\
\hline $\begin{array}{l}\text { Probability } \\
\text { adjective }\end{array}$ & $\begin{array}{l}\text { possible, likely, unlikely, clear, } \\
\text { definite, certain, probable }\end{array}$ & 'It is likely to result in failure.' \\
\hline Noun & $\begin{array}{l}\text { assumption, claim, probability } \\
\text { possibility, estimate, suggestion, }\end{array}$ & 'We estimate that one in five marriages end in divorce.' \\
\hline Adverb & $\begin{array}{l}\text { Practically, presumably, clearly, } \\
\text { probably, conversely, possibly, } \\
\text { perhaps, definitely, certainly, } \\
\text { virtually apparently, completely }\end{array}$ & $\begin{array}{l}\text { 'There is, perhaps, a good reason why she chose to } \\
\text { write in the first person.' }\end{array}$ \\
\hline $\begin{array}{l}\text { Adverb } \\
\text { frequency }\end{array}$ & $\begin{array}{l}\text { often, occasionally, generally, } \\
\text { usually, sometimes, normally, } \\
\text { frequently, always, rarely, never, } \\
\text { seldom }\end{array}$ & 'Sometimes it could produce a lot profit.' \\
\hline “If” clause & if true, if anything & $\begin{array}{l}\text { 'If true, our study contradicts the myth that men make } \\
\text { better managers than women.' }\end{array}$ \\
\hline $\begin{array}{l}\text { Compound } \\
\text { hedges }\end{array}$ & $\begin{array}{l}\text { seems reasonable, looks probable, } \\
\text { may be suggested }\end{array}$ & $\begin{array}{l}\text { Such compound hedges can be double hedges (it may } \\
\text { be suggested that; it seems likely that; it would indicate } \\
\text { that; this probably indicates); treble hedges (it seems } \\
\text { reasonable to assume that); quadruple hedges (it would } \\
\text { seem somewhat unlikely that. }\end{array}$ \\
\hline Fillers & $\begin{array}{l}\text { you know, you see, by the way, sort } \\
\text { of, well, hmm, uhm, uhh, uh..huh, all } \\
\text { I know, I mean, yeah, like }\end{array}$ & You know, it can help them to fulfill the daily needs. \\
\hline
\end{tabular}




\subsection{Experimental Studies}

Neary-Sundquist (2013) explored the utilization of hedges (moderating articulations like I think or sort of) in the speech of students of English at various proficiency levels and additionally of native speakers. Hedges were utilized to direct the power of an expression or the sureness of its substance and thus assume an essential part in relational communication. The consequences of this investigation demonstrated that students for the most part underuse hedges in comparison with native speakers, in spite of the fact that students at the utmost proficiency level utilized hedges at a rate tantamount to that of native speakers. The scope of hedges is for the most part identical crosswise over levels. In both the rate and the scope of hedge utilization, striking changes seem to happen between the second most elevated and the most astounding proficiency level.

Dousti and Eslami Rasekh (2016) inspected the nearness of conceivable contrasts in the linguistic behavior of male and female ELT real students regarding the usage of hedging devices in their interpersonal communications. To do as such, three discussion sessions in a solitary gendered setting were independently recorded for male and female members. Frequency counts and chi-square were utilized to analyze the gathered data. The discoveries of the examination demonstrated females' more inclination to utilize hedging devices. In addition, a concentration group interview was held. The recognized subjects uncovered distinctive elements of hedging devices for female members including their longing to welcome others' viewpoints, to be friendly, and to assemble great compatibility with their conversationalists. In any case, the members stoutly dismissed their lower societal position as the explanation behind their more utilization of hedges.

Rosanti and Jaelani (2016) intended to depict lexical hedges utilized by female and male respondents in spoken language and to analyze lexical hedges utilized by female and male students in debates. The technique utilized as a part of this examination was descriptive-qualitative strategy. By utilizing the framework of hedges proposed by Namasaraev (1997), it is inferred that there are differences amongst female and male respondents' inclination in picking word of lexical hedges. Female respondents tended to utilize more lexical hedges than male respondents. In such manner, female respondents most frequently utilized lexical hedges of fillers, for example, hmm, uhh, you know in their expressions; while male respondents most as often as possible utilized lexical hedges of fillers, for example, $I$ think, uhh, hmm in their utterances. Female respondents had wide range assortment in picking expressions of lexical hedges while male respondents were not sufficiently productive in selecting the expressions of lexical hedges. It was appeared by the number of lexical hedges utilized as a part of giving idea in debate setting.

\section{Methodology}

\subsection{Design of the Study}

This study employed a descriptive design; using semi-structured interviews as the research instrument and using frequency for data analysis.

\subsection{Participants}

Forty (20 male and 20 female) Iranian upper-intermediate EFL learners majoring in TEFL were selected from Islamic Azad University of Abadan, Iran. They were all native speakers of Persian and their age ranged from 20 to 24 . The participants were chosen based on non-probability convenience sampling procedure. To address their homogeneity, it must be mentioned that all these students had successfully passed BA university entrance exam which is a competitive

one in Iran. Moreover, they all had passed their speaking/listening 1 course in the previous semester. Accordingly, it can be concluded that these participants enjoyed the same level of proficiency. The selected participants were assigned into two equal groups namely male group $(n=20)$ and female group $(n=20)$. 


\subsection{Instruments}

\subsubsection{Semi-structured Interviews}

After selecting the participants, a semi-structured interview was used to explore both female and male participants' use of lexical hedges. As proposed by Fielding and Thomas (2001), a focus group interview which requires the participants to negotiate their ideas was conducted. All female and male participants were present to express their opinions in the interview session.

\subsection{Data Collection}

In the first step, 40 homogeneous upper-intermediate students were chosen from Islamic Azad University of Abadan, Iran and assigned into two equal groups, namely a male group and a female group. According to Brown, Dovido, and Ellyson (1990), males and females' language may be affected by the chosen topics. To tackle with the previously mentioned problem, 15 topics were given to another student sample doing their fifth semester to put the topics in rank regarding the degree to which they can be considered as gender-biased topics. Then the eight topics which were judged to be less biased were chosen for the discussion sessions.

The discussions around the following topics were used as data: Social Networking, Technology, Poverty, Election, Love, Sports, Plastic Surgery, and Cooking. The researchers asked each participant to give some opinions related to the topic which was given by the writer. The participants were asked for permission to record their voice; however, the main purpose of the study was not explained to avoid the impact of participants' possible biases in their use of hedging devices. Therefore, every respondent idea was recorded and analyzed. It should be mentioned that to ensure that participants had been accustomed to the presence of the researchers and the influence of researchers' presence on the performance of the participants was diminished to the minimum, only the attained data of the last five discussion sessions were chosen for the analysis.

The data were classified based on the kinds of lexical hedges and respondent gender. The types of lexical hedges regarding the language features, such as fillers, lexical verb, modal auxiliary verb, compound hedges, and adverb of frequency were classified (Rosanti \& Jaelani, 2016). The total of lexical hedges was based on its properties and all of the lexical hedges which were applied by female respondents and male respondents were counted. The female and male students' orientation in utilizing lexical hedges was analyzed. Each discussion was lasted 40 minutes and the overall amount of recorded discussions for the five sessions was three hours and twenty minutes for each group.

\subsection{Data Analysis}

After collecting the needed data, the researchers transcribed them and used the frequency to point out the differences between the performances of the two groups during the discussion topics. Finally, the researchers analyzed and tabulated the data with the help of SPSS (Statistical Package for Social Science) software, version 25 and Microsoft Excel, version 2016.

\section{Results}

After getting the data from females' and males' respondents, the writers then put it on the tables. Then, the writers separated the data based on their gender. In this study, the writers explored the female and male respondents' propensity in choosing words when they expressed and evinced their idea by utilizing lexical hedges. 
Table 2. Data of lexical hedges as fillers

Filers

\begin{tabular}{|c|c|c|}
\hline Features & Female & Male \\
\hline Like & 4 & 2 \\
\hline Uhh & 24 & 13 \\
\hline Uhm & 9 & 3 \\
\hline $\mathrm{Hmm}$ & 21 & 8 \\
\hline Well & 8 & 4 \\
\hline You know & 16 & 6 \\
\hline You see & 4 & 1 \\
\hline By the way & 3 & 2 \\
\hline Sort of & 2 & 0 \\
\hline All I know & 3 & 3 \\
\hline I mean & 9 & 6 \\
\hline Yeah & 17 & 9 \\
\hline As I probably know & 4 & 2 \\
\hline Total & 124 & 59 \\
\hline
\end{tabular}

As Table 2 reveals, the female respondents used 124 words of lexical hedges as fillers, there are; like, $u h h, u h m, h m m$, well, you know, you see, by the way, sort of, all I know, I mean, yeah, as I probably know. While, the male respondents' tendency utilized 59 words of lexical hedges as fillers. 
Table 3. Data of lexical hedges as lexical verb

\begin{tabular}{lll} 
Lexical Verb & Female & Male \\
\hline Features & 4 & 1 \\
I believe that & 3 & 2 \\
It is believed that & 4 & 3 \\
I assume that & 1 & 1 \\
It is assumed that & 2 & 3 \\
Some people assume & 0 & 0 \\
It is indicated that & 1 & 1 \\
Tend to & 1 & 2 \\
I suggest that & 4 & 18 \\
It is suggested that & 52 & 1 \\
I think & 22 & 0 \\
It seems & 4 & 1 \\
It seems like & 2 & 35 \\
I suppose that & & 2 \\
\hline
\end{tabular}

Regarding using the lexical verb as lexical hedges as presented in Table 3, the female respondents' tendency used 52 words of lexical hedges as lexical verb in contrast to male group who used 35. 
Table 4. Data of lexical hedges as modal auxiliary verbs

\begin{tabular}{lll}
\hline Modal Auxiliary Verbs & & \\
\hline Features & Female & Male \\
\hline Could be & 1 & 3 \\
Can be & 3 & 2 \\
Should be & 2 & 1 \\
Would be & 2 & 1 \\
May & 5 & 2 \\
Total & 13 & 9 \\
\hline
\end{tabular}

Table 4 indicates that Modal Auxiliary Verbs were used by females $(n=13)$ more than males $(n=9)$.

Table 5. Data of lexical hedges as compound hedges

\begin{tabular}{lll} 
Compound hedges & Female & Male \\
\hline Features & 2 & 1 \\
\hline It may be impossible & 4 & 2 \\
It will probably & 1 & 2 \\
It may be started & 2 & 1 \\
It may be suggested & 3 & 0 \\
It might be suggested & 12 & 6 \\
Total & & \\
\hline
\end{tabular}

Table 5 reports the male and female groups' scores in using Compound hedges; as it is shown clearly above, the frequency of female group is 12 and the frequency of male group is 6 . Therefore, it can be concluded that the female group used more Compound hedges in their discussions. 
Table 6. Data of lexical hedges as adverb of frequency

\begin{tabular}{lll} 
Adverb of Frequency & Female & Male \\
\hline Features & 4 & 2 \\
\hline Sometimes & 6 & 4 \\
Usually & 5 & 3 \\
always & 2 & 0 \\
often & 4 & 2 \\
generally & 5 & 4 \\
never & 26 & 15 \\
\hline Total & 26 \\
\hline
\end{tabular}

In Table 6, the performance of male and female groups is presented in using adverb of frequency as a type of lexical hedges. Both groups were different; the female group used more adverb of frequency (26) in their discussions.

Table 7. The total data of lexical hedges in both groups

\begin{tabular}{lll}
\hline Lexical Hedges & Female & Male \\
\hline Filers & 124 & 59 \\
Lexical Verb & 52 & 35 \\
Modal Auxiliary Verbs & 13 & 9 \\
Compound hedges & 12 & 6 \\
Adverb of Frequency & 26 & 15 \\
\hline Total & 227 & 124 \\
\hline
\end{tabular}

The aggregate of female and male respondents who picked the expressions of lexical hedges was various. Female respondents were for the most part utilized fillers in communicating their assessments while doing the discussion. In this manner, it demonstrated that female respondents were more dynamic than male respondents in giving their ideas. It has been demonstrated by the aggregate of words delivered by female and male respondents. In the table above (Table 7), we could see additionally the distinctions of male and female respondents' inclination in picking the expressions of lexical hedges. The aggregate of data on the table above, which demonstrated the score of female students in creating words of lexical hedges, were 227 words. While the aggregate of male learners in using words of 
lexical hedges were 124 words. Accordingly, there were the differences amongst female and male respondents' propensity in picking the words of lexical hedges. It was revealed by the aggregate of lexical hedges utilized amongst female and male respondents in giving their ideas. In can also be concluded that among the lexical hedges, Filers were used most frequently by both female and male students in their academic spoken language.

Debate and discussion were utilized as the media for the researchers to get the information about the comparative research amongst female and male respondents. The researchers concentrated the material on the utilization of lexical hedges amongst female and male respondents in giving their ideas, since it could be utilized as an apparatus that demonstrated the differences amongst female and male respondents in utilizing lexical hedges. Watching a few pictures was additionally utilized as a part of this exploration to make the outcome precisely. From the information that has been gathered, female respondents tended to pick the words of lexical hedges more than male respondents. To find out about female and male respondents' propensity in picking words particularly in utilizing lexical hedges, the researchers utilized the discussion as a media to incite both female and male students to express their ideas in utilizing lexical hedges. From the information gathered, the researchers place it into graphic which clarified about female and male respondents' inclination in picking lexical hedges in expressing their views.

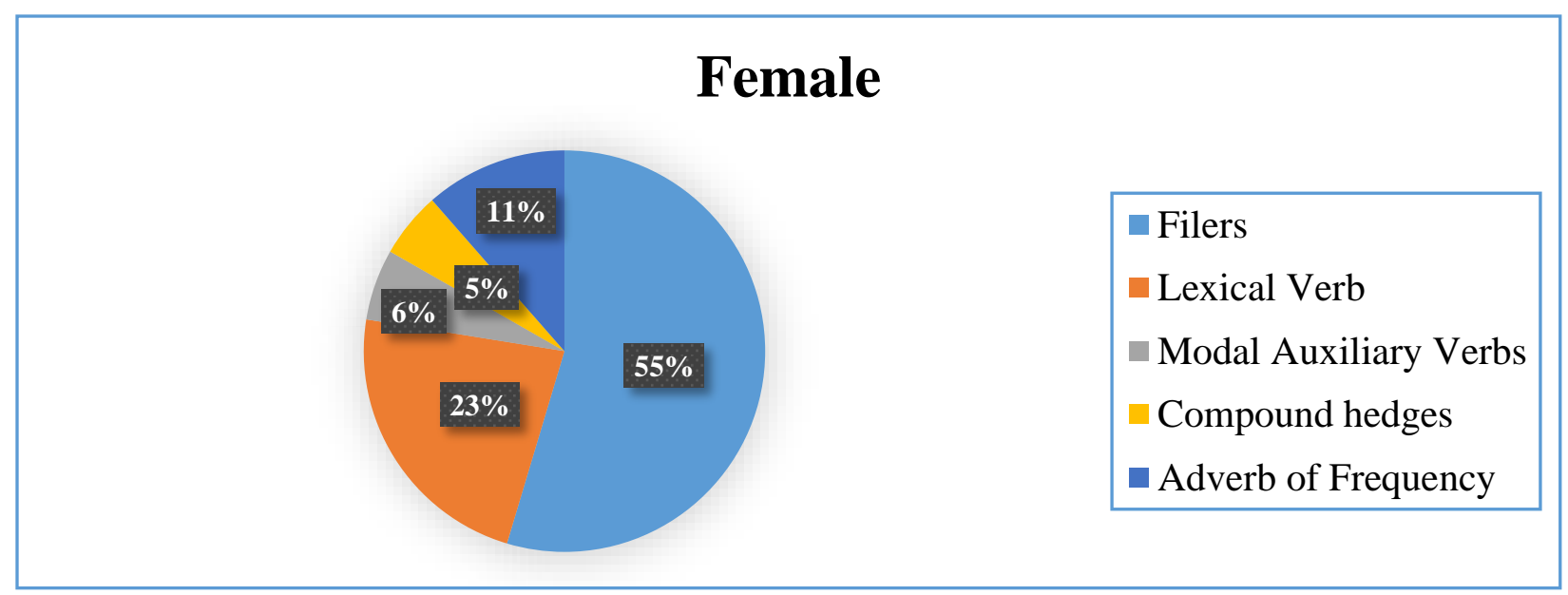

Graph 1. Female respondents' tendency in using lexical hedges

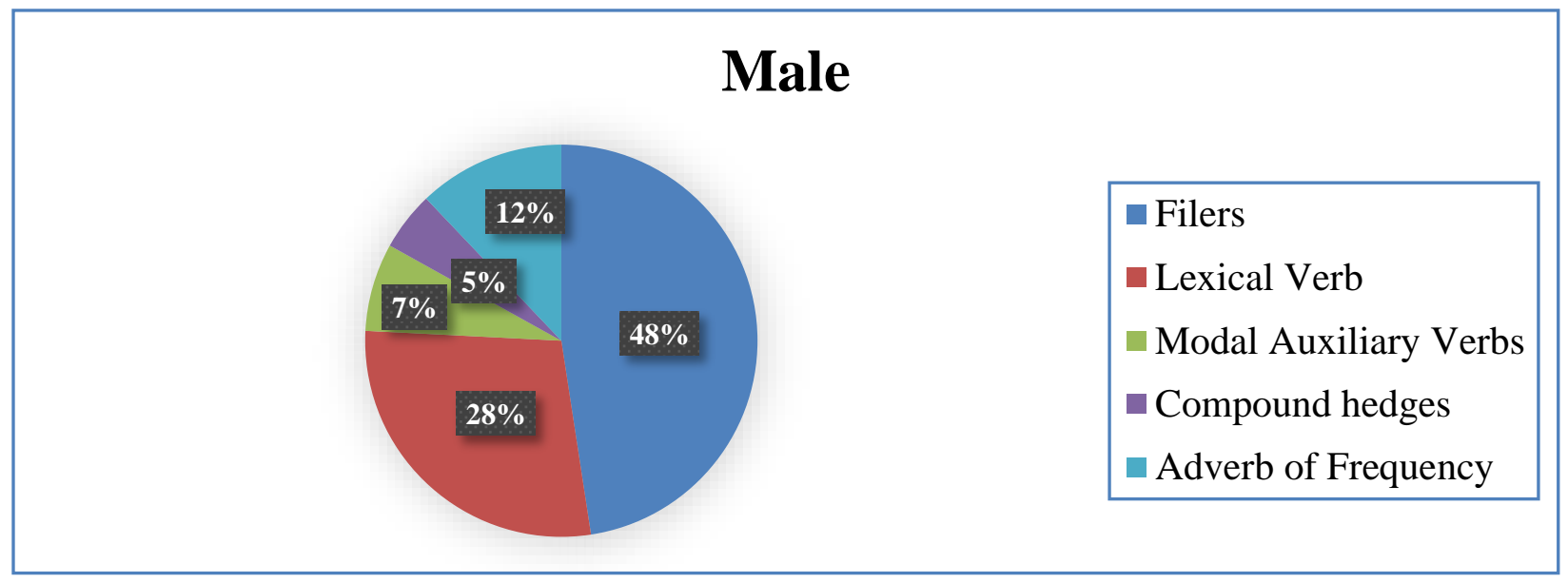

Graph 2. Male respondents' tendency in using lexical hedges 
The graphics above demonstrated that male responders were less than female responders in picking the words of lexical hedges. It showed that female respondents were more productive in utilizing the words of lexical hedges than male respondents for this situation. Principal discussion on the study was about female and male respondents' propensity in picking words of lexical hedges when they communicated their ideas. It likewise clarified about female and male respondents' words selections. The researchers found the differences amongst female and male respondents in selecting the words of lexical hedges. To answer the second research question addressing the presence of any differences between genders in terms of the employed hedges in Academic Spoken Language, Chi-square test was run. Table 4 is indicative of the results of this test. The Chi-square test for independence demonstrated a significant association between gender and hedge utilization, $\mathrm{X}^{2}(11, n=40)=33.905, p=0.0$, phi $=.921$.

Table 8. Chi-square tests

\begin{tabular}{llll}
\hline & Value & df & $\begin{array}{l}\text { Asymptotic Significance } \\
(2 \text {-sided })\end{array}$ \\
\hline Pearson Chi-Square & $33.905^{\mathrm{a}}$ & 11 & .000 \\
Likelihood Ratio & 45.891 & 11 & .000 \\
Linear-by-Linear Association & 25.797 & 1 & .000 \\
N of Valid Cases & 40 & & \\
\hline
\end{tabular}

a. 22 cells $(91.7 \%)$ have expected count less than 5 . The minimum expected count is .50 .

Although the obtained results divulged the presence of significant difference between genders' hedge use, the value of Cramer's V is 0.921 which is reported to be a strong effect size (See Table 9).

Table 9. Symmetric measures

\begin{tabular}{llll}
\hline & & Value & Approximate Significance \\
\hline Nominal by Nominal & Phi & .921 & .000 \\
\cline { 2 - 3 } & Cramer's V & .921 & .000 \\
\hline N of Valid Cases & & 40 & \\
\hline
\end{tabular}

\section{Discussion}

Generally speaking, there are three sorts of consecutive places of lexical hedges in the utterances as initial, medial, and final (Rosanti \& Jaelani, 2016). Each sequence turns out to perform their function separately. The initial position uncovers that lexical hedges frequently demonstrate as starting marker of an articulation, self-extension, and utterance signal. While, the medial position uncovers that lexical hedges frequently show elaboration mostly and it likewise works as a repair signal. The last sort of consecutive places of lexical hedges is as final position. It frequently 
demonstrates as affirmation searcher and turn-handling signal into rising inflection. Managing the kinds of consecutive places of lexical kedges in the articulations, in this case, the authors analyzed from the information transcript that there were two successive places of lexical hedges in the expressions as initial and medial position which were appeared by the responders. In other words, there was no final position of lexical hedges utilized by the responders.

In this study, the researchers analyzed from the information transcript that the expressions of words of lexical hedges, for example: I think, you know, you see, some people assume that, All I know, it will probably, I believe that happen in the onset of the sentence as initial position of hedges. However, being in the onset does not generally literally allude to be in the first word of articulation. Or maybe, the position alludes to the start of a sentence level which may be gone before by incomplete articulations. The initial position does not truly need to be the main word being expressed. The instance shows that the sequential places of lexical hedges as final position happened subsequently after a speaker's identity and it could be utilized to move a topic and choose an alternate speaker to take turn. The subsequent case of the initial position above shows that it happens precisely in the new sentence, after a period where can be in the start of talk. Along these lines, the initial position uncovers that lexical hedges frequently show as initial marker of an expression, self-extension, and utterance signal.

There are numerous words of lexical hedges which are utilized as the medial position as indicated by the information transcript which was demonstrated by the respondents. The researchers analyzed that the words of lexical hedges, for example: uhh, uhm, hmm, yeah, like, well, sort of, by the way, I suppose that, I mean, as I probably know, it is indicated that, it may be suggested that, it is assumed that, it is believed that, sometimes, it seems, it seems like, may, should be, could be, can be, would be, tend to, perhaps, sometimes, it is suggested that occur in the middle of the sentence as medial position of hedges. The words of lexical hedges which are the most frequently utilized as the medial position can be amidst clauses, states, or even single lexical unit. It was often utilized as a method for slowing down the time traverse as speakers are searching for the next upcoming words to produce. Lexical hedges in the medial position fill in as a repair signal which is not just an issue of mistake however change of syntactic level is likewise included. While, the researchers additionally dissected another function of the words of lexical hedges in the medial position, for example, uhh, uhm, hmm, yeah as delay marker when the speakers are not sure about what they disclose to the interlocutors (Rosanti \& Jaelani, 2016).

One distinguished feature of the utilization of lexical hedges in final position is frequently trailed by rising intonation. The function of the utilization of lexical hedges as final position has an affirmation searcher and turn-yielder when it denotes the finish of articulation. Like the initial position, the final position does not only allude to the end of utterance which prompts another turn yet it likewise alludes to the end of a turn constructional unit inside a flood of talk performed by a similar speaker. Subsequently, the final position uncovers that lexical hedges regularly demonstrate as affirmation searcher and turn-handling of signal. In the information transcript, there was no final position of lexical hedges utilized by the respondents.

In a nutshell, the discoveries of the current research demonstrated that females' speech was intensely hedged in contrast with that of male members regardless of their all participation in a similar scholarly community. This obtained result is precisely in line with Lakoff's (1975) claim describing females' speech as having broad occurrences of hedging devices. Similar discoveries are additionally announced in various different examinations carried out in this field (Akhmaliah, 2009; Ansarin \& Bathaie, 2011; Zaini, Hazirah, Saadiyah, \& Kemboja, 2012); however, the consequences of the investigation led by Samaie, Khosravian, and Boghayeri (2014) are in contrast with the outcomes of the present study.

Moreover, the present study also supports the findings of Rosanti and Jaelani (2016) who investigated lexical hedges utilized by female and male students in spoken language and to analyze lexical hedges used by female and male students in debate. They concluded that that there are differences between female and male respondents' tendency in selecting word of lexical hedges. Female respondents tended to utilize more lexical hedges than male respondents. 
They also concluded that female respondents have wide range variety in picking words of lexical hedges while male respondents were not productive enough in selecting the words of lexical hedges.

The plausible reason that the female group used lexical hedges frequently in their academic spoken language is that they employed hedges to welcome and simplify others' participation in the discussions to reach general concurrence, to mitigate and curtail their utterances to indicate their concern and reverence for interlocutors' ideas and their feasible discordances, and finally as a tool to be friendly. Furthermore, refuting political inequalities and determining the incisive role of context in which the speaking was occurring were the other noticed issues.

One of the other primary topics of the present study emphasizes the usage of hedges as the result of the context in which discussion occurs. In other words, particular parts of circumstance were accepted to assume the focal part in modifying the speech to be in accordance with the objective of discussion. Female members likewise said their desire to amass the conversational participation and demanded that more use of hedges did not mirror their insufficiency of learning. Female members determined the preference of being mindful to others' ideas as their primary goal in discussion instead of rivaling others to dictate their own thoughts.

Hereupon, it can be concluded that distinctive social objectives are pursued by males and females. This theory determines the presence of various sub-cultures for males and females. It additionally indicates male and females' distinctive behaviors in comparable social settings which are established in adjustment of varying cultural closures and standards, which are all exhibited in the utilized language by males and females.

\section{Conclusion}

The present study which aimed to compare gender differences in the use of lexical hedges in academic spoken language indicated numerous differences of tendency were found between female and male respondents in selecting the words of lexical hedges in giving ideas. Female responders tended to utilize more lexical hedges than male respondents. It was revealed by female responders produced words of lexical hedges which were 227 words. In this case, the female responders utilized lexical hedges as fillers such as; hmm, uhh, you know, yeah in their utterances while the total of male responders in producing words of lexical hedges were 124 words. The male respondents used lexical hedges as fillers such as; I think, uhh, yeah in their utterances. Female respondents had broad range variegation in picking words of lexical hedges while male respondents were not sufficiently productive in selecting the words of lexical hedges. It was indicated based on the total of lexical hedges that they utilized in giving idea in debate and discussion process. The female respondents had the tendency to give lengthy views than male respondents about the theme of debate. Furthermore, the male respondents tended to give a short and succinct viewpoint than female responders.

\section{References}

Adams, S., \& Hicks, W. (2001). Interviewing for journalists (Media Skills). London; New York: Routledge. https://trove.nla.gov.au/version/43725878

Akhmaliah. R. (2009). An analysis of language features in blogs of female undergraduates. Unpublished B.A. project paper. Universiti Kebangsaan Malaysia.

Ansarin, A. A., \& Bathaie, M. (2011). Hedging as an index of gender realization in research articles in applied linguistics. Iranian Journal of Applied Language, 3(2), 85-108. doi: 10.22111/ijals.2011.1010

Atkinson, D. (1999). Scientific discourse in sociohistorical context: The philosophical transactions of the royal society of London, 1675-1975. Mahwah, NJ: Erlbaum.

Biber, D., \& Leech, G. (1999). Grammar of spoken and written English. London: Pearson Longman. 
Brown, C. E., Dovido, J. F., \& Ellyson, S. L. (1990). Reducing sex differences in visual displays of dominance: Knowledge is power. Personality and Social Psychology Bulletin, 16(6), 358-368. doi.org/10.1177/0146167290162015.

Brown, P., \& Levinson, S. C. (1978). Universals in language usage: Politeness phenomena. In E. N Goody (Ed.), Questions and politeness. Cambridge: Cambridge University Press.

Brown, P., \& Levinson, S. C. (1987). Politeness: Some universals in language usage. Cambridge: Cambridge University Press.

Chafe, W. (1986). Evidentially in English conversation and academic writing. In Evidentiality: The Linguistic Coding of Epistemology. By Wallace Chafe, and Johanna Nichols, 261-272. New York: Ablex.

Crystal, D., \& Davy, D. (1975). Investigating English style. London: Longman.

Dousti, M., \& Eslami Rasekh, A. (2016). ELT students' gender differences in the use of hedges in interpersonal interactions: A mixed method approach applied. Journal of Applied Linguistics and Language Research, 3(1), 217-231. doi.org/10.5296/ijl. v5i6.4012

Eckert, P. (2003). Elephants in the room. Journal of sociolinguistics, 7(3), 392-397. doi: 10.1111/1467-9481.00231.

Fielding, N., \& Thomas. H. (2001). Qualitative interviewing. In N. Gibert (ed.), Researching social life (2 ${ }^{\text {nd }}$ edition). London: Sage.

Greenbaum, S., \& Quirk, R. (1990). A student's grammar of the English language. London: Longman.

Halliday, M. A. K. (1985). Spoken and written language (2nd Ed.). London: Oxford University Press.

Holmes, J. (1983). Speaking English with the appropriate degree of conviction. In C. Brumfit (Ed.), Learning and teaching languages for communication: Applied linguistics perspectives. London: BAAL.

Holmes, J. (1990). Hedges and boosters in women's and men's speech. Language and Communication, 10(3), 185205. doi.org/10.1016/0271-5309(90)90002.

Holmes, J. (2008). An introduction to sociolinguistics (3rd Ed.). London: Pearson Education Limited.

House, J., \& Kasper, G. (1981). Politeness markers in English and in German. In F. Coulmas (Ed.). Conversational routines. The Hague: Mouton de Gruyter.

Hübler, A. (1983). Understatements and hedges in English. Amsterdam/ Philadelphia: Benjamins.

Hyland, K. (1998). Hedging in scientific research articles. Amsterdam/Philadelphia: John Benjamins Publishing Company.

James, A. R. (1983). Compromisers in English: A cross-disciplinary approach to their interpersonal significance. Journal of Pragmatics 7(2), 191 -206. https://doi.org/10.1016/0378-2166(83)90052-8.

Lakoff, G. (1972). Hedges: A study of meaning criteria and the logic of fuzzy concepts. In P. Peranteau., J. Levi., \& G. Phares. (Eds.). Papers from the Eighth regional meeting of Chicago linguistic society. Chicago: Chicago University Press.

Leech, G., Deuchar, M., \& Hoogenraad, R. (1982). English grammar for today. London: Macmillan Press Ltd.

Namasaraev, V. (1997). Hedging in Russian academic writing in sociological texts. Moscow: Publishing Company.

Neary-Sundquist, C. (2013). The use of hedges in the speech of ESL learners. Elia, 1(13), 149-174. doi: http://dx.doi.org/10.12795/elia.2013.i13.05 
Rosanti, E. D., \& Jaelani, A. (2016). The use of lexical hedges in spoken language by female and male students. Electronic Journals of UIKA Bogor, 16(1), 29-39. https://www ejournal.uikabogor.ac.id/index.php/ENGLISH/article/download/251/248

Samaie, M., Khosravian, F., \& Boghayeri, M. (2014). The frequency and types of hedges in research article introductions by Persian and English native authors. Science Direct, 98(6), 1678-1685. doi: 10.1016/j.sbspro.2014.03.593

Tannen, D. (1982). Spoken and written language: Exploring orality and literacy. Norwood, N.J.: ABLEX Pub. Corp. https://www.amazon.com/Spoken-Written-Language-Exploring-Discourse/dp/0893910996

Tong, R. (2009). Feminist thought (3rd Ed.). Colorado: Westview Press. https://excoradfeminisms.files.wordpress.com/2010/07/feminist_thought_a_more_comprehensive_intro.pdf

Zaini, A., Hazirah, A., Saadiyah, D., \& Kemboja, I. (2012). Gender differences in the language use of Malaysian teen bloggers. GEMA Online ${ }^{\mathrm{TM}}$ Journal of Language Studies, 12(1), 105-124. http://ejournal.ukm.my/gema/article/view/24

Zimmerman, D., \& West, C. (1975). Sex roles, interruptions and silences in conversation. In Thorne, B. and Henley, N. (eds) (1975) Language and sex: Difference and dominance. Rowley: Newbury House. 